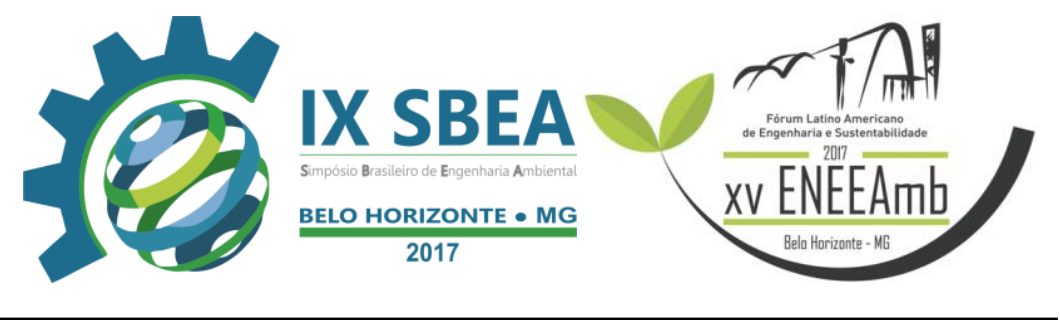

\title{
ANÁLISE QUALIQUANTITATIVA DOS IMPACTOS AMBIENTAIS E A PISCICULTURA INTENSIVA: OS EFLUENTES COMO FONTE DE IMPACTO
}

Relrison da Costa Favacho - relrisoneng@ gmail.com

Universidade do Estado do Pará

Celiane Lima dos Santos- celianelima.eng@gmail.com

Universidade do Estado do Pará

Lorena Saraiva Viana - lorenaengamb20@gmail.com

Universidade do Estado do Pará

Ruana Regina Negrão de Souza-ruengamb@ hotmail.com

Universidade do Estado do Pará 


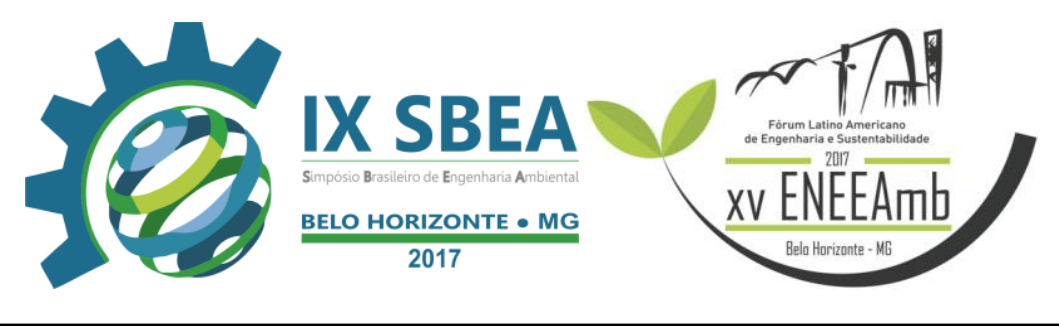

\section{RESUMO}

A piscicultura é caracterizada pelo cultivo de peixes e por ser uma atividade que exerce alteração das condições iniciais de corpos hídricos pela influência do empreendimento, se faz necessário a aplicação da Avaliação de Impactos Ambientais, utilizado como instrumento de gestão ambiental. Com as alterações nas características naturais, os corpos hídricos sofrem alterações em parâmetros de qualidade da água, como a disponibilidade de oxigênio dissolvido, turbidez, nível de nitrogênio $(\mathrm{N})$, etc. Um dos principais impactos ambientais causados pela piscicultura é o acumulo de matéria orgânica e elevação dos teores de Nitrogênio e Fosforo. O objetivo do presente trabalho foi analisar qualitativamente os principais impactos ambientais causados pela prática da piscicultura, com ênfase na consequência do lançamento do efluente sem tratamento no corpo hídrico. Para alcançar esse objetivo utilizou-se a metodologia observativa, sistêmica, complementada pelo levantamento de dados documentais, com recorte temporal compreendido entre 2008 a 2016 e o CONAMA n. 001, de 23 de janeiro de 1986, no qual obteve-se como resultado, o total de 13 artigos que relaciona a atividade piscicultora com o aumento de matéria orgânica e Fósforo e Nitrogênio. Deste modo a piscicultura é uma atividade com alto grau de impacto e degradação aos corpos hídricos, o que aumenta a necessidade da aplicação de técnicas e medidas de controle ambiental como a Avaliação de Impactos Ambientais (AIA).

Palavras-chave: Piscicultura, Impactos ambientais, Recursos hídricos.

\section{INTRODUÇÃO/OBJETIVO}

Desde a antiguidade, a humanidade utiliza dos recursos naturais para abastecimento, subsistência e consumo. Atividades como a caça e a pesca foram desenvolvidas de forma rebuscada no início, sendo depois aperfeiçoada e direcionadas para outros fins, como o financeiro. Dentro do conceito de desenvolvimento, a aquicultura surge com relevância, instigando o âmbito econômico (OLIVEIRA, 2009).

Ademais, a aquicultura é uma atividade de cultivo de organismos dos quais o ciclo de vida dos seres aquáticos, se dá total ou relativamente em meio aquático em 


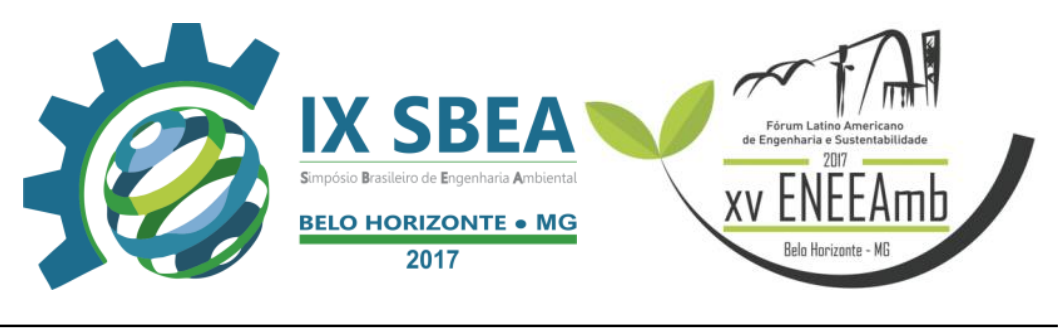

condições naturais, incluindo a propriedade do estoque perante cultivo, equiparada à atividade agropecuária (BRASIL, 2009, grifo nosso).

Nesse contexto, a piscicultura é um ramo da aquicultura que concerne ao cultivo de peixes, dividida de acordo com as características produtivas, métodos empregados e tipo de produção alcançada, desse modo, é subdividida em extensiva ou intensiva. É importante salientar que a piscicultura é uma atividade que integra o setor primário (ROCHA \& VITAL, 2012).

A partir dessa vertente, a principal produtora, no quesito aquicultura, com ênfase na piscicultura, apresenta um índice igual a 67,3\%, provinda da República Popular Da China e cerca de $22,3 \%$ da região da Ásia-Pacífico. Também contando com 0,6\% da produção mundial ostentada pela América Latina, Caribe e América do Norte (SUBASINGHE et al., 2009). A nível nacional, a produção aquícola foi cerca de 289.000t no ano de 2008, representando uma receita de mais de R\$ 2 bilhões, prevalecendo o cultivo de peixes de água doce, mais de $70 \%$ da produção (MACEDO \& SIPAUBA-TAVARES, 2010).

Quanto a isso, sabe-se que o crescimento da atividade de produção se dá por fatores de adaptação de espécies à parâmetros físicos, biológicos e antrópicos, os quais podem ser alterados, por exemplo, pelo descarte do efluente da piscicultura de maneira inadequada, o que produz desequilíbrio em múltiplos níveis, que vão desde o social, ambiental ao econômico (MOURA et al., 2014).

Além disso, os impactos causados pela atividade de cultivo de peixes requerem muito cuidado, visto que causa alterações nas condições naturais das áreas diretamente e indiretamente afetadas pela atividade. Em suma, a piscicultura torna-se uma atividade degradante à medida que aumenta a produtividade intensificando os impactos causados no meio, sendo necessária a avaliação de impacto ambiental na área (SILVA \& CAMARGO, 2008).

Nesse contexto, a resolução do Conselho Nacional do Meio Ambiente CONAMA, n. 001:1986, define que as atividades que alteram as características físicas, biológicas e químicas no meio, que afetem direta ou indiretamente a saúde, bem-estar 


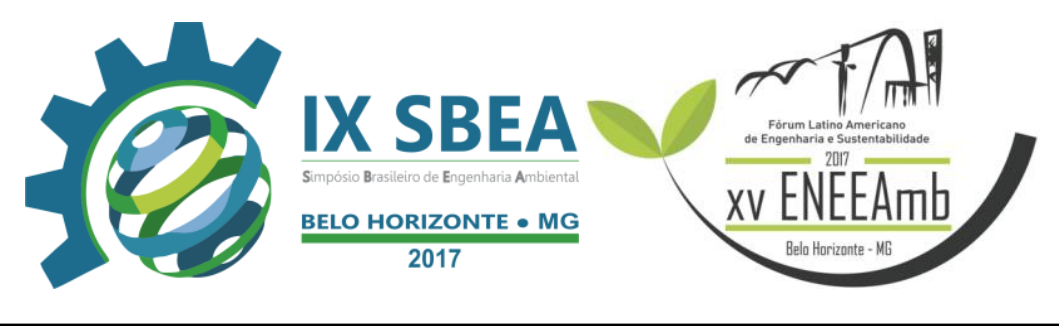

da população, circunstancias sanitárias e estéticas, a qualidade dos recursos naturais e outros, causam impactos ambientais (BRASIL, 1986).

Ademais, a Avaliação de Impacto Ambiental - AIA, é utilizada como instrumento imprescindível na gestão ambiental, pois define métodos para a minimização dos efeitos que atingem diretamente o meio de forma negativa, e corresponde à indicação de medidas de prevenção e precaução quando prognosticadas sua necessidade (LOPES \& RIBEIRO, 2016).

Em face desses argumentos, o presente trabalho tem como objetivo analisar qualitativamente os principais impactos ambientais causados pela prática da piscicultura intensiva, em ênfase nas consequências do lançamento do efluente sem tratamento no corpo hídrico.

\section{METODOLOGIA}

Este é um estudo de revisão sistemática descritiva, no qual os critérios de seleção foram artigos que relacionavam a piscicultura com impactos ambientais, e desenvolveu-se através de consultas com produção cientifica indexada nas seguintes bases eletrônicas de dados: Serviço Integrado de Bibliotecas e Informação (SIBI),ScientificElectronic LibraryOnline (SCIELO), CentroRegional Universitário de Espírito Santo do Pinhal (UNIPINHAL), AssociaçãoAmigos da Natureza da Alta Paulista (ANAP), Biblioteca Digital Brasileira de Teses e Dissertações (BDTD), Base de Dados da Pesquisa Agropecuária(BDPA) e Portal dos Periódicos Científicos da Universidade Estadual de Londrina - UEL.

A revisão indica para uma questão especifica e utiliza métodos sistemáticos para identificar, selecionar e avaliar criticamente os estudos, para coletar e analisar os dados desse estudo a serem incluídas na revisão. O recorte temporal abrangeu o período compreendido de junho de 2008 a dezembro de 2016 e o CONAMA n. 001, de 23 de janeiro de 1986.

Após levantamento, seguiram-se as análises qualiquantitativa dos dados através de estatísticas descritivas e frequência relativa e absoluta, que foram verificados por 


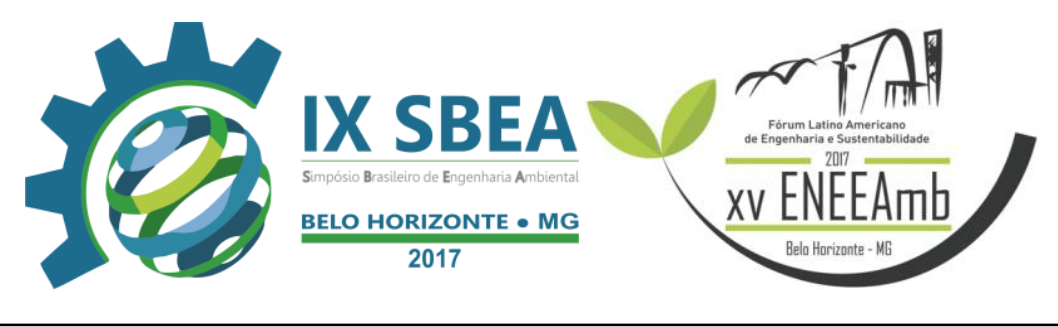

incidência de impactos relacionados aos efluentes da piscicultura. Foi verificado nas diversas modalidades de piscicultura a incidência de matéria orgânica e acumulo de nutrientes.

\section{RESULTADOS E DISCUSSÃO}

Entre a consulta de dados realizada, foram encontrados 61 (80,26\%) artigos científicos que abordam sobre o cultivo de peixes, $13(17,10 \%)$ artigos e $2(2,63 \%)$ teses relacionando a piscultura com impactos ambientais.

Em relação aos impactos causados pela atividade piscicultora, foram encontrados cinco artigos, que abordam o tema, na base de dados da SCIELO, no SIBI foram encontradas no total de dois artigos, na ANAP foi encontrado apenas um artigo, bem como foi encontrado na UNIPINHAL apenas um artigo, no PORTAL DE PERIODICO CIENTICO DA UEL foi encontrado um artigo, no BDPA um artigo e no BDTD duas teses, Tabela 1.

\begin{tabular}{|c|c|l|c|}
\hline $\begin{array}{c}\text { Base de Dados } \\
\text { Total }\end{array}$ & Total & \multicolumn{1}{|c|}{ Impactos } & $\begin{array}{c}\text { Artigos e } \\
\text { teses }\end{array}$ \\
\hline SIBI & 2 & Acúmulode Matéria Orgânica & 02 \\
\cline { 3 - 4 } & & $\begin{array}{l}\text { Aumento das Concentrações de } \\
\text { N e P }\end{array}$ & 01 \\
\hline SCIELO & 5 & Acúmulo de Matéria Orgânica & 02 \\
\cline { 3 - 4 } & & $\begin{array}{l}\text { Aumento das Concentrações de } \\
\text { N e P }\end{array}$ & 03 \\
\hline UNIPINHAL & 1 & Acúmulo de Matéria Orgânica & 01 \\
\hline ANAP & 1 & $\begin{array}{l}\text { Aumento das Concentrações de } \\
\text { N e P }\end{array}$ & 01 \\
\hline $\begin{array}{c}\text { PORTAL DE } \\
\text { PERIODICOS } \\
\text { CIENTIFICOS } \\
\text { DA UEL }\end{array}$ & 1 & Acúmulo de Matéria Orgânica & 01 \\
\hline BDTD & 2 & Acúmulo de Matéria Orgânica & 02 \\
\hline BDPA & 1 & Acúmulo de Matéria Orgânica & 01 \\
\hline
\end{tabular}




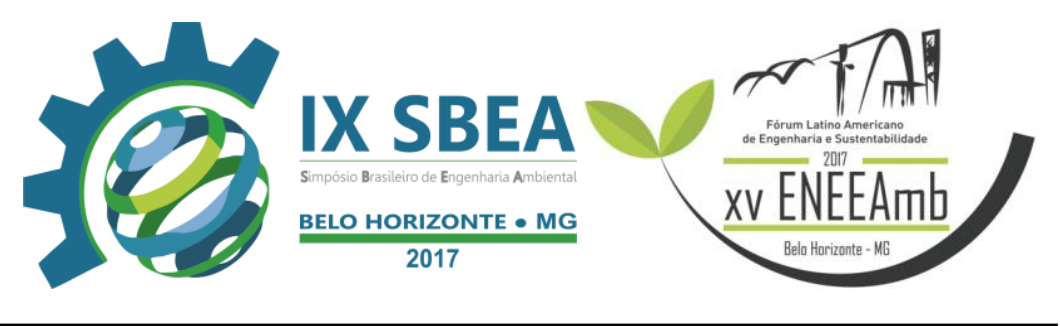

TOTAL DE

TRABALHOS

13

Tabela 1: Quantidade de artigos por assuntos relacionado aos impactos causados pela piscicultura.

Com os dados obtidos através dos trabalhos estudados, foi possível obter uma análise estatística pela frequência absoluta dos impactos causados pela piscicultura, conforme a figura 1 .

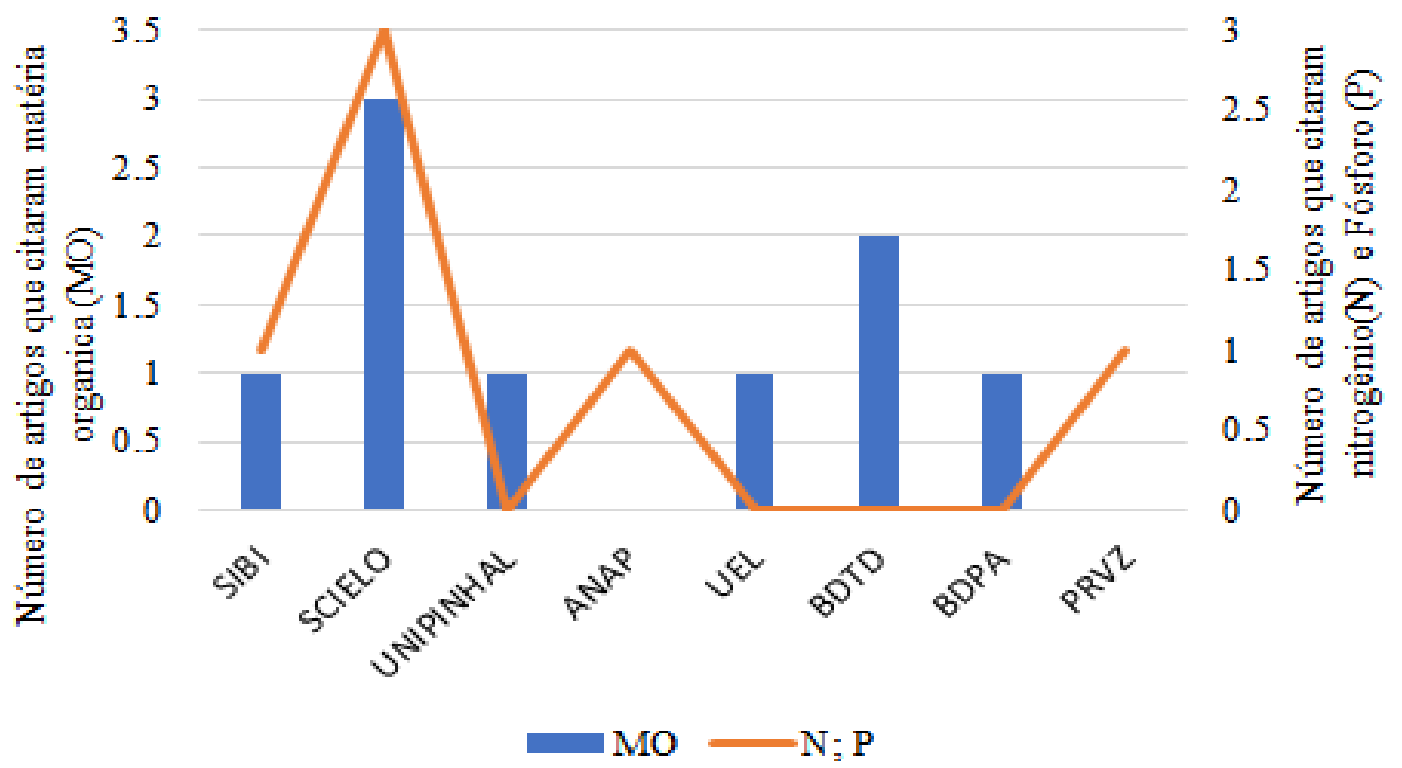

Figura 1:Banco de dados e periódicos consultados acerca da citação de matéria orgânica e nutrientes na água em piscicultura.

Os resultados obtidos demonstram que os principais impactos gerados pela piscicultura são o acumulo de matéria orgânica e elevação da concentração de Nitrogênio $(\mathrm{N})$ e Fósforo $(\mathrm{P})$. A alteração na quantidade de nutrientes disponível no meio aquático é provinda do excesso de ração e biomassa animal, servindo de substratos para o crescimento de macrófitas aquáticas.

Neste contexto, apenas 1 autor relacionou o efeito dessas alterações com o processo de eutrofização. O referido autor menciona que este processo gera outros 


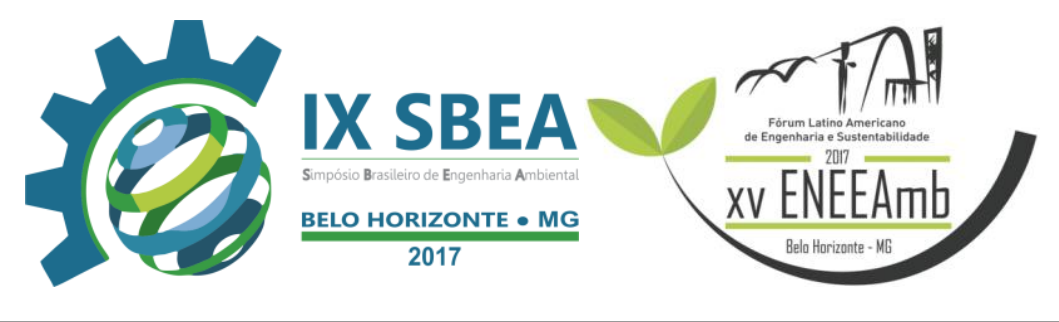

impactos, pois, a eutrofização é ocasionada pelo o crescimento de macrófitas aquáticas, evidenciando maior consumo de oxigênio dissolvido (OD), além disso, se tornam como barreiras para refração da luz, impedindo a reposição do oxigênio através da fotossíntese biótica aquática e difusão do gás Oxigênio (O2), havendo, desta forma, mortandade de peixes.

Ademais, as teses obtidas comprovam que apesar de algumas espécies de macrófitas aquáticas, por exemplo, a Salvinia molesta, atuarem como fitorremediadoras, quando são encontradas em grande quantidade no meio, causam desiquilíbrio nas condições naturais, afetando a quantidade excessiva de biomassa vegetal.

Assim, os autores discorrem que a falta do estudo da quantidade de nutrientes necessária para uma alimentação balanceada destinada aos peixes ocasionam o excesso de ração oferecida e consequentemente o acumulo de matéria orgânica, haja vista que no período de despesca, esse acumulo é maior, devido à ausência de consumidores.

Em suma, foi observado que todos os artigos revisados apresentam como principal consequência da eutrofização, a redução do teor de oxigênio dissolvido pelo consumo das macrófitas aquáticas, peixes, também pela oxidação da matéria orgânica.

Diante do exposto o fluxograma, interpretado na figura 2 , representa de forma

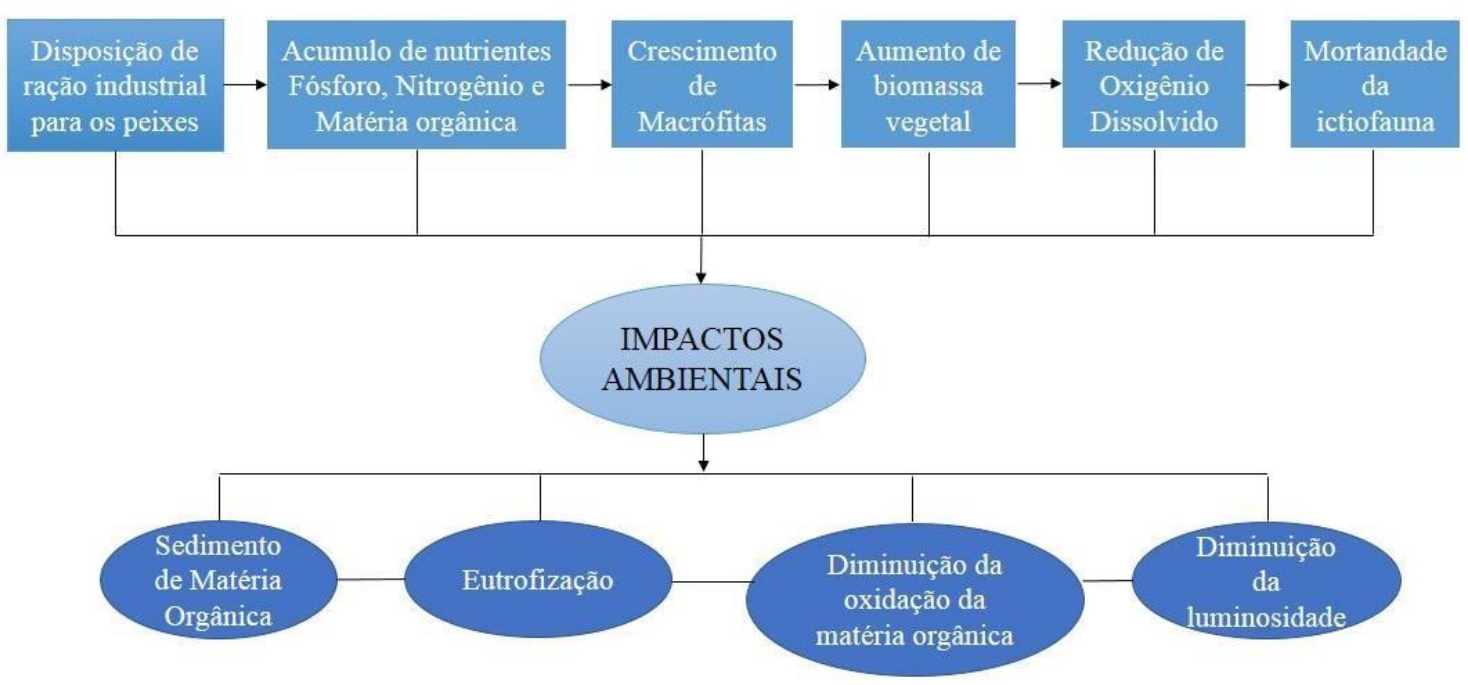




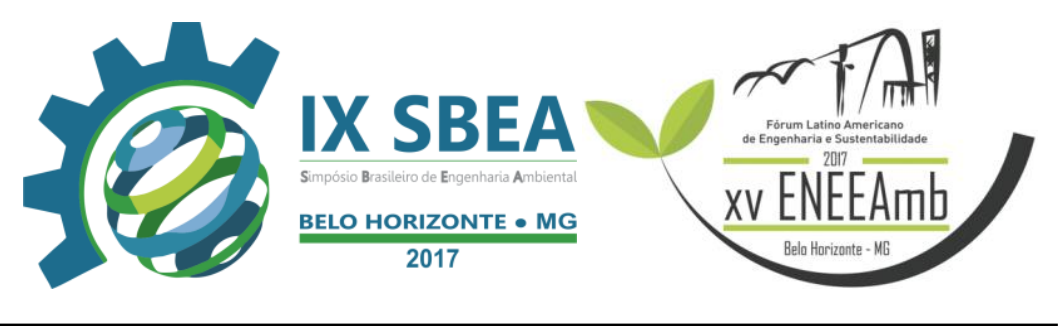

simplificada a relação que os autores atribuem às grandes concentrações de nutrientes e matéria orgânica com os efeitos (impactos indiretos).

Figura 2: Impactos ambientais causados pela piscicultura relacionados pelos autores

\section{CONCLUSÕES/RECOMENDAÇÕES}

A maioria dos sistemas de piscicultura no Brasil não possui tratamento de efluente e apresenta riscos a qualidade da água do corpo receptor. O efluente da atividade de cultivo de peixes causa elevação nos valores de turbidez, sólidos suspensos, nutrientes e redução do oxigênio dissolvido. Consequentemente, o corpo hídrico tende a permanecer com as concentrações de nutrientes desde o ponto de lançamento a montante até $1 \mathrm{~km}$ da jusante.

A piscicultura é uma atividade com alto grau de impacto e degradação a corpos hídricos, e necessita de aprofundamento cientifico, no que diz respeito ao desenvolvimento de técnicas e métodos, afim de estipular e definir medidas mitigatórias na composição do estudo de Avaliações de Impactos Ambientais (AIA), dado a relevância econômica a atividade estará melhor enquadrada no contexto sustentável atual quando, na implantação do empreendimento, com finalidade a redução de potencialidades negativas e elevação das potencialidades ambientalmente positivas.

\section{REFERÊNCIAS BIBLIOGRÁFICAS}

BRASIL. Lei n. 11.959, de 29 de junho de 2009. Política Nacional de Desenvolvimento Sustentável da Aquicultura e da Pesca: Legislação Federal. Disponível em: <http://www.planalto.gov.br/ccivil_03/_ato20072010/2009/lei/111959.htm>. Acesso em: 18. Abr. 2017.

BRASIL. Ministério Do Meio Ambiente, Conselho Nacional Do Meio Ambiente, CONAMA. Resolução CONAMA n. 001:86, de 23 de janeiro: - In resoluções, 1986. 


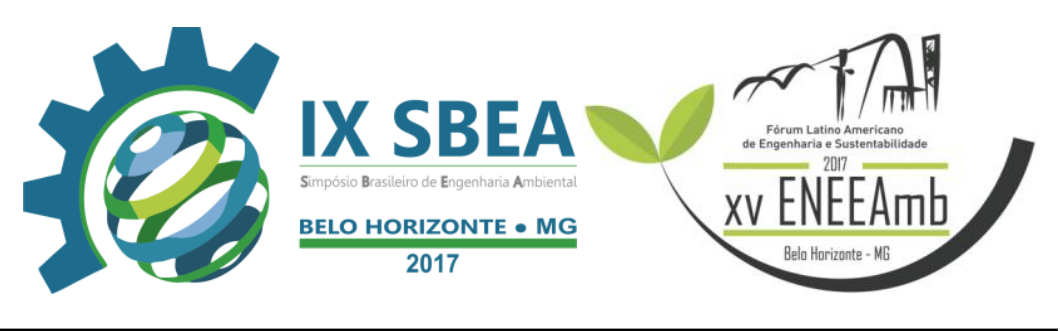

Disponível em: <http://www.mma.gov.br/port/conama/res/res86/res0186.html > Acesso em: 18. Abr. 2017.

LOPES, L. C. P.; RIBEIRO, J. C. J. O Papel da Avaliação de Impacto Ambiental para Adoção de Medidas Compensatórias. Revista de Direito Ambiental e Socio ambientalismo, São Paulo, v. 2, n. 1, p. 148-169, mai. 2016.

MACEDO, C. F.; SIPAUBA-TAVARES, L. H. Eutrofização e qualidade da água na piscicultura: consequências e recomendações. Boletim do Instituto de Pesca, São Paulo, v. 36, n. 2, p. 149-163, nov. 2010.

MOURA, R. S. T. et al. Sedimentação de nutrientes e material particulado em reservatório sob influência de atividades de piscicultura no semiárido do Rio Grande do Norte. Revista Química Nova. 2014. v. 37, n. 8, p.1283-1288.

OLIVEIRA, R. C. de. O Panorama Da Aquicultura No Brasil: a Prática Com Foco Na Sustentabilidade. Revista Intertox de Toxicologia, São Paulo, v. 2, n. 1, p.71 -89, fev. 2009.

ROCHA, B. C. G.; VITAL, T. A piscicultura em tanque-rede no município de Petrolândia - PE: um arranjo produtivo local em construção. Revista em Agronegócios e Meio Ambiente, Maringá, v. 5, n. 3, p.475-492, dez. 2012.

SILVA, G. G. H.; CAMARGO, A. F. M. Impacto das atividades de aquicultura e sistemas de tratamento de tratamento de efluentes com macrófitas aquáticas: relato de caso. Boletim do Instituto de Pesca, São Paulo, v. 34, n. 1, p.163-173, fev. 2008.

SUBASINGHE, R. et al. Global Aquaculture And Its Role In Sustainable Development. Reviews In Aquaculture. Roma, [s.1.], v. 1, n. 1, p.2-9, mar. 2009. 